\title{
Docosahexaenoic acid (DHA), essentiality and requirements: why and how to provide supplementation
}

\author{
By Alfonso Valenzuela ${ }^{1},{ }^{2 \star}$ B. Julio Sanhueza ${ }^{1}$, and Susana Nieto ${ }^{1}$ \\ ${ }^{1}$ Laboratory of Lipids and Antioxidants, INTA, University of Chile, Casilla 138-11, Santiago, Chile. \\ ${ }^{2}$ School of Medicine, University of los Andes, Santiago, Chile. \\ ${ }^{*}$ Corresponding author: e-mail: avalenzu @ inta.cl
}

\section{RESUMEN}

Ácido docosahexaenoico (DHA), esencialidad y requerimientos: porqué y cómo proporcionar (o suministrar) la suplementación.

Los lípidos comprenden entre el 50-60\% de la estructura del cerebro, y el ácido docosahexaenoico (C22:6, DHA) es el ácido graso poliinsaturado de cadena larga de los fosfolípidos del cerebro más importante, siendo el $25 \%$ del total de los ácidos grasos. La mayor parte del DHA presente en el cerebro se incorpora durante el desarrollo de este, el que comienza a la $26^{\text {ava }}$ semana gestacional, generando una alta demanda por el ácido graso hasta los dos años de edad. El DHA se requiere en el desarrollo cerebral durante la diferenciación neuronal y glial, y durante la mielinización y la sinaptogénesis neuronal. El ácido graso debe ser incorporado a los lípidos del cerebro preformado ya que menos de un $5 \%$ de su precursor, el ácido alfa linolénico (LNA), se convierte a DHA. El feto humano tiene una capacidad muy limitada para sintetizar DHA a partir de LNA, por lo cual debe ser aportado por fuentes de origen materno. EI DHA puede ser aportado por la madre a partir de tres fuentes principales; desde el tejido adiposo, cual es el principal reservorio del ácido graso, a partir de la biosíntesis desde el precursor LNA, la que ocurre principalmente en el hígado, o como ácido graso preformado proveniente de la dieta. Durante el período postnatal, el DHA es aportado por la madre al recién nacido a través de la leche. La nutrición occidental aporta baja cantidad de LNA y de DHA, y los Comités de Expertos en Nutrición sugieren que la madre debe recibir una suplementación con DHA durante el embarazo y la lactancia. Actualmente, la suplementación con DHA puede ser aportada a partir de diferentes fuentes; como DHA puro, como un etil éster, como aceite obtenido de microalgas, a partir de los fosfolípidos de la yema de huevo, o en la forma de un sn-2 monoacilglicerol. En esta revisión se discute sobre la evidencia que apoya la suplementación del recién nacido con $\mathrm{DHA}$, la necesidad de la suplementación de la madre durante el embarazo y la lactancia, y sobre cuales son al presente las alternativas para proveer la suplementación con DHA.

PALABRAS-CLAVE: Ácido docosahexaenoico - DesarroIlo cerebral - Fuentes de ácido docosahexaenoico - Suplementación con ácido docosahexaenoico.

\section{SUMMARY}

Docosahexaenoic acid (DHA) essentiality and requirementes: why and how to provide supplementation

Lipids comprize from $50-60 \%$ of the structural matter of the brain and docosahexaenoic acid (C22:6, DHA) is the most important omega-3 long-chain polyunsaturated fatty acid in the brain phospholipids comprizing $25 \%$ of the total fatty acids of the grey matter. The majority of the DHA present in the human brain is incorporated during the brain growth spurt which starts at week 26 of gestation and imposes a high demand for the fatty acid until about 2 years of age. DHA is required during brain development when neuronal and glial differentiation and migration, and active myelination and synaptogenesis take place. The fatty acid must be incorporated into the brain lipids as preformed DHA because less than $5 \%$ of its precursor (alpha linolenic acid, LNA) is converted to DHA. The human foetus has a limited ability to synthesize DHA from LNA, and therefore it must be largely supplied from maternal sources. Maternal DHA available for foetal nutrition can be provided from three main sources: adipose tissue, which is the main reservoir for the fatty acid; through biosynthesis from the precursor LNA, which occurs mainly in the liver; and as preformed DHA from dietary sources. In the postnatal period DHA is provided by the mother to the newborn through milk secretion. Western nutrition provides low LNA and DHA and Expert Nutrition Committees suggest that mothers should receive DHA supplementation during pregnancy and lactation. At present DHA supplementation can be provided from different sources: as purified free DHA, as an ethyl ester derivative, extracted from single-cell algae oils, from egg yolk phospholipids, or in the form of sn-2 DHA monoacylglycerol. In this review we revise and discuss the evidence of DHA requirements for the newborn, the need for maternal supplementation during pregnancy and nursing, and the alternatives at present for providing DHA supplementation.

KEY-WORDS: Docosahexaenoic acid - Brain development - Docosahexaenoic acid supplementation - Docosahexaenoic acid sources.

\section{INTRODUCTION}

Second to adipose tissue, the brain is the most lipid-containing organ in the body. Lipids comprize from $50-60 \%$ of the structural matter of the brain on a dry weight basis, or $10 \%$ on a weight/weight basis (Sastry, 1985) and seventy percent of energy during fetal growth is devoted to brain development (Crawford, 2000). The average adult female and male brains weigh $1.25 \mathrm{~kg}$ and $1.4 \mathrm{~kg}$, respectively (Cockburn, 2003). At birth the full term infant human brain weighs about $350 \mathrm{~g}$. However, a premature infant born at 24 weeks has an average brain weight 
of only $100 \mathrm{~g}$. During the first year of life, the full term infant brain weight increases by $750 \mathrm{~g}$ to a total weight of $1.1 \mathrm{~kg}$. Approximately $47 \%$ of this increase in brain weight takes place in the cerebral cortex. The cortical dry weight increase is $125 \mathrm{~g}$, of which $75 \mathrm{~g}$ are lipids, predominantly phospholipids (Cockburn, 1999). Phospholipids make up about one quarter of the solid mater of the brain and are integral to the vascular system on which the brain depends. The major phospholipids in neuronal membranes are phosphatidylcholine (PC), phosphatidylethanolamine (PE), phosphatidylserine (PS), and phosphatidylinositol (PI), In addition to phospholipids, there are also sphingomyelins (phosphosphingolipids) and cerebrosides (glycosphingolipids). PC confers structural stability to neuronal membranes (Culliss \& DeKrui., 1979), while carboxyl groups of PS function as ionexchange sites (Cook et al., 1972).

Docosahexaenoic acid (C22:6, DHA), together with arachidonic acid (C20:4 AA) are, respectively, the major omega-3 and omega- 6 long-chain polyunsaturated fatty acids (LC-PUFA) in the mammalian brain and in retinal phospholipids, a tissue that from the phylogenetic point of view can be considered of neural origin (Jeffrey et al., 2001). DHA constitutes approximately $25 \%$ of the total fatty acids of the phospholipids of the gray matter and $50 \%$ of the fatty acids in retinal rod outer segments, which represent almost the only polyunsaturated fatty acid (Anderson, 1970). DHA preferentially cross-links with proteins and through their high degree of unsaturation mediates the activity of membrane bound enzymes at the neuronal cells. It is believed that DHA plays an important role in regulating the fluidity of neuronal membranes and thus the efficiency of neuroelectrical signal transmission (Kurlak \& Stephenson, 1999). The majority of DHA present in the human brain is incorporated during the brain growth spurt which starts at week 26 of gestation and imposes a high demand for the fatty acid until about 2 years of age. DHA is required during brain development when neuronal and glial differentiation and migration, and active myelination and synaptogenesis take place. Neuronal differentiation and migration are essentially prenatal processes (Jumpsen et al., 1997), but gliogenesis, neuronal myelination and synaptogenesis are predominantly postnatal events occurring in the first 18 months of postnatal life (Morgane et al., 1993). DHA together with AA are highly conserved LC-PUFA in the brain because less than $15 \%$ of these fatty acids is beta oxidized, in contrast to alpha linolenic acid (C18:3, omega-3, LNA) the precursor of DHA, and of linoleic acid (C18:2, omega-6, LA) the precursor of $A A$, which are converted in a small proportion to the respective LC-PUFA in the brain, the rest being oxidized (Leyton et al., 1987). Preformed DHA is incorporated directly into the developing brain in an order of magnitude greater than synthesis from LNA (Sinclair, 1975). Less than 5\% of LNA is converted to DHA, $5 \%-10 \%$ is used for the biosynthesis of cholesterol in the brain rather than for DHA biosynthesis and up to $80 \%$ is oxidized (Cunnane, 2001). Once accreted in the brain, DHA is tenaciously retained once neural development has occurred (Salem et al., 2001).

\section{ABOUT DHA ESSENTIALITY}

The foetus and the placenta are fully dependent on the maternal LC-PUFA supply for their growth and development. Although the major deposition of fat occurs in the human foetus during the third trimester, the placental vessels and the uterine vasculature are dependent on LC-PUFA supplied by the mother for eicosanoid and docosanoid formation from the moment of conception. The human foetus has a limited ability to synthesize DHA from its precursor LNA, and therefore it must be largely supplied from maternal sources (Cunnane, 2001). It has been proposed that foetal elongase/desaturase enzyme systems are immature and unable to synthesize the required amount of DHA for brain and visual development (Uauy et al., 2000). This failure of synthesis may have been exacerbated by the lower hepatic reserves of DHA associated with premature delivery. Foetal growth represents largely drawn upon maternal DHA stores and a limitation in the size of the maternal omega-3 LC-PUFA stores may be critically detrimental to foetal growth and development (Van Houwelingen et al., 1992). Maternal DHA available to foetal nutrition can be provided from three main sources: adipose tissue, which is the main reservoir for the fatty acid; through biosynthesis from the precursor LNA, which occurs mainly in the liver; and as preformed DHA from dietary sources. Maternal supplies of DHA are transferred to the foetus through the placenta, a tissue highly permeable to LC-PUFA, and to the neonate through breast milk which contains a small but significant amount of DHA. The placenta plays a crucial role in the mother-to-foetal fatty acid transport. The tissue exerts a specific capturing and release of DHA and $A A$ to foetal circulation in terms that the relative percentage of these LC-PUFA increases in phospholipids progressively from maternal blood to placenta and to foetal blood, liver, and brain. Through this process, termed biomagnification (Crawford et al., 1976), the placenta may direct and control the specific delivery of omega-3 and omega-6 LC-PUFA to meet the requirements of the growing foetal brain. A placental plasma membrane binding protein that preferentially binds LC-PUFA over nonessential fatty acids and which favors the unidirectional flow of maternal LC-PUFA to the foetus was described by Dutta-Roy (2000). LNA is also transferred to the foetus from the mother, however preformed DHA is incorporated to foetal tissues by least one order of magnitude higher than LNA-derived DHA (SheaffGreiner et al., 1997). It has been reported that $80 \%$ of human foetal brain DHA accrues between weeks 26 and 40 of gestation, which means that during this gestational period the placenta must increase its 
selective capturing and release of fatty acid, and presumably of AA.

It has been demonstrated that omega-3 and omega-6 LC-PUFA are selectively transported from the liver to the placenta and then to the brain in the form of sn-2 docosahexaenyl and sn-2 arachidonyl lysophosphatidylcholine (DHA-lysoPC and AAlysoPC, respectively) bound to albumin, which appear to be a preferential form of transport over the corresponding unesterified form (LemaitreDelaunay et al., 1999). This transport appears to be exclusive for the brain, because other organs, such as the liver, kidney, and heart, do not exhibit such a preference (Lagarde et al., 2001). This suggests the existence of a recognition system of the lysophosphatidylcholine species in the brain (Thiés et al., 1992). However, in the brain DHA is incorporated mainly to the sn-2 position of PS and PE, and secondary to $P C$. This means that a specific transfer of DHA must occur from DHA-lysoPC to PS and PE. The brain vascular epithelium has the particular ability to acylate and/or hydrolyze these phospholipid species. PS is synthesized from preexisting $P C$ and $P E$ through a base-exchange reaction and subsequently decarboxylated to $P E$ by phosphatidylserine decarboxylase (Thiés et al., 1992). AA is also incorporated to either the sn-2 or to the sn-3 position of PS and PC. sn-3 Position is preferentially occupied by AA when the sn-2 position is substituted by DHA.

DHA is mostly concentrated in the phospholipids that form neural growth cones, synaptosomes, microsomes, and mitochondria (Suzuki et al., 1997) and presumably is involved in the synaptic function. $A A$ is more regularly distributed to the total neural membranes. The specific participation for DHA in neuronal functions, such as vesicular storage and the release of neurotransmitters, neurotransmitter reuptake transporters, presynaptic and postsynaptic receptor function, and second messenger responsiveness, have not been extensively studied and remain as a very fertile research field (Fernstrom, 2000). LNA is not accreted in the brain, but it is transported by an unidentified mechanism, presumably similar to DHA, to glial cells where it is elongated/desaturated to be converted to DHA, and then transported to the neurons, which do not have the capability to transform LNA to DHA (Moore et al., 1991). Information about AA biosynthesis from LA to the glial cells is not available but presumably LA may also be transformed to AA by the same elongation/ desaturation mechanism. DHA and AA are recycled within brain cell phospholipids independently of each other, suggesting that recycling is regulated independently by DHA- and AA-selective enzymes (Contreras et al., 2001).

\section{DHA REQUIREMENTS}

During the third trimester of human development, omega-3 and omega-6 LC-PUFAs accrue in fetal tissues as essential components of brain phospholipids. This is the period where the brain increases in cell size, cell number, and cell type, therefore brain lipids must be increased rapidly during the last weeks of gestation. Although haemato-encephalic barrier is highly permeable to LNA and LA, these two fatty acids are not accreted into the brain during the last trimester of pregnancy as are their derivatives DHA and AA. This means that the two LC-PUFAs must be accreted as preformed fatty acids because as discussed, the foetal brain does not have the ability to desaturate/elongate LNA and LA to DHA and AA, respectively (Clandinin et al., 1981). As the fetal liver, presumably, is not totally able to meet with the brain requirements of DHA and $A A$ because of the immaturity of the desaturation/ elongation enzymatic system, DHA and AA must be provided by the mother. These LC-PUFAs are accreted at different rates during intra-uterine life compared to extra-uterine life. Brain DHA accretion is higher during intra-uterine life, whereas AA accretion is higher in the post-delivery period. This means that the higher DHA requirements are mostly produced at the pre-natal period and therefore the fatty acid must be provided by the mother (Clandinin, 1999). A progressive decline in maternal LC-PUFA, which affects more markedly to omega- 3 than omega- 6 fatty acids, has been observed during pregnancy. Infants born of multiparous mothers have lower DHA levels than those of primiparous mothers and maternal DHA stores are not fully replenished in the interval between successive pregnancies (Al et al., 1995). This may be relevant in women from under developed countries where the first pregnancy occurs at a very young age followed by successive pregnancies with short intervals in between which may not allow enough time to provide the DHA required for optimal foetal development.

During the post-natal period omega-3 and omega-6 LC-PUFA are provided to the newborn through milk secretion. Human milk contains a small amount of DHA (0.2-0.4\%) and AA (0.5-0.6\%) (Jensen, 1999) which are, however, enough to meet the LC-PUFA requirements during the breastfeeding period (Koletzko et al., 1992). Cow's milk contains AA but not DHA. These are one of the reasons why cow's milk can not replace mother's milk during the suckling period. When mother's breast milk supply is suspended or reduced, babies should be fed formulas which contain omega-3 and omega- 6 fatty acids. Some formulas contain LNA and LA, mostly those in the US and Canada, but others also contain $\mathrm{DHA}$ and $\mathrm{AA}$, such as the formulas used in Europe, Asia and South America (Koletzko \& Sinclair, 1999). Since 2002 infant formulas with added DHA +AA for infants born full-term and prematurely became available in the US (Koo, 2003). The rationale for adding LC-PUFA to infant formula was primarily because of their presence in large quantities in brain, the retina, and in human milk. In addition, infants who are fed formulas containing LC-PUFAs and breastfed infants have comparable DHA and $A A$ levels in red blood cells and plasma, in contrast to the lower DHA and $A A$ levels in those who are fed infant formulas containing only LNA and LA (Carlson et al., 1991). 


\section{THE NEED FOR DHA SUPPLEMENTATION}

Since the report by Hoefer \& Hardy (1929) several studies have reported that children who are breastfed score higher on tests of cognitive development than children who are formula fed (Anderson et al., 1999), and that this effect becomes more pronounced with increasing duration of breastfeeding (Gale \& Martyn, 1996). In premature infants, the evidence that human milk may promote neurodevelopment and higher intellectual quotient is stronger. Also, the association between the duration of breastfeeding and adult intelligence has been established (Mortensen et al., 2002). Although human milk contains a myriad of components, some of them not fully identified, it has been suggested that omega- 6 and omega-3 LC-PUFAs are relevant in the development of intellectual abilities. Recommendations to add omega- 6 and omega- 3 LC-PUFAs to formulas either to replace its original composition of LNA and LA, or to increase the total content of PUFAs and LC-PUFAs have been proposed from different research groups. However, is there proof of the benefits for infant development from feeding infant formulas containing omega- 6 and omega-3 LC-PUFAs? Studies comparing children who were breastfed with children who were fed infant formula have reported an association between breast feeding and intellectual development (Colombo, 2001). Several studies have evaluated whether supplementing formulas for fullterm or premature infants with DHA increases circulation levels of the fatty acid and enhance cognitive, memory, and visual development (Das, 2003). Nevertheless, results are controversial. While some researchers do not support the addition of DHA to formulas because they have not observed enhancement in developmental parameters during the first months after birth, others claim improvement in visual and or cognitive abilities after post-natal DHA supplementation. Agostoni et al. (1997) demonstrated a direct influence of omega-3 LCPUFA supplemented formula on the development quotient of healthy, full term infants. They evaluated neurodevelopment by the Brunet-Lézine psychomotor development test at 4 months of age, comparing with breast-fed infants and those fed with standard formula. Formula-fed infants who received omega-3 LC-PUFAs supplementation and breast-fed infants scored better than standard formula-fed infants. They suggest that formula supplementation with omega-3 LC-PUFAs can benefit full-term infants in their neurodevelopmental performance. Willats et al. (1998) assessed the cognitive behaviour of a group of full-term infants who, for their first 4 postnatal months had been randomized to receive a formula supplemented and not supplemented with AA and DHA. At 10 months of age, the LC-PUFAs supplemented infants performed significantly better on the means-end problem-solving test used than did infants who had received the non supplemented formula. In addition, Hansen et al. (1997) found that infants who were fed formulas enriched with DHA and AA had improved growth relative to infants who were fed standard formula. Contrasting to the observation of the preceding authors, Lucas et al. (1999) observed no evidence of a beneficial or adverse effect on cognitive or motor development in full-term babies who were fed formula with or without LC-PUFAs at 18 months of age when evaluated according to the Bayley Mental and Psychomotor Development test. Auestad et al. (2001) more recently observed that adding AA + DHA to formulas does not improve growth, visual acuity, information processing, language, or temperament in healthy, full-term infants during the first month after birth. Malcolm et al. (2003) demonstrated that maternal DHA supplementation during pregnancy did not enhance maturation of visual evoked potential in healthy full-term infants. However, these results show an association between the DHA status of infants at term and early postnatal development of the pattern-reversal visual evoked potential, suggesting that DHA status itself may influence maturation of the central visual pathway. The correlation between LC-PUFAs at birth or after some months of life and cognitive performance at several years of life has been also studied. Birch et al. (2000) reported no correlation between DHA at 12 months and developmental outcomes at 18 months. More recently Bakker et al. (2003) do not provide evidence for a positive association between cognitive performance at 7 years and LC-PUFAs status at birth or at 7 years. However, as discussed by Mostofsky (2001), and Gibson \& Makrides, (2001) the experimental design, methodologies, and environmental differences play a central role in studies investigating the effect of nutritional factors, such as DHA, on cognitive and visual development during infancy. Salem et al. (2001) in a critical review about omega-3 and omega-6 LC-PUFA supplementation for full-term infants concluded that "given the present state of knowledge from human and animal studies on changes in the neural function associated with a low DHA status, coupled with biochemical and nutritional studies indicating the loss of DHA in both peripheral tissues and the nervous system when preformed DHA is not fed, it is clear that a prudent course of action would be to supply sources of preformed DHA to the infant diet". Expert Nutrition Committees suggest that the mother should receive DHA supplementation during pregnancy and lactation, a daily amount of $300 \mathrm{mg} / \mathrm{d}$ is the recommended intake (Simopoulos et al., 1999). Recently Cockburn (2003) in an exhaustive analysis revised the role of LC-PUFAs, and of other nutrients such as liposoluble vitamins, cholesterol, and lecithin, in infant psychomotor development. With respect to LC-PUFAs the author concluded that the research does not support that adding $\mathrm{DHA}$ and $\mathrm{AA}$ to formulae containing $10 \%$ energy as LA and 1\% energy as LNA may enhance growth, visual acuity, information processing, general development, language or temperament in healthy, full- term infants during the first 14 months after birth. 
According to the information available it appears not be possible at present to reach a consensus about the role of LC-PUFAs on psychomotor development. Nevertheless, there is consensus about the importance of DHA and AA for neural system structure and function. However, differences in measurement of psychomotor capabilities due to the amount of these LC-PUFAs supplied before, during, and after the gestational period, may obey to a metabolic "fine tuning" that some researchers are able to measure and evaluate, but others are not.

\section{DIGESTION AND ABSORPTION OF DHA-CONTAINING LIPIDS}

The normal pathway of dietary triacylglycerol digestion involves hydrolysis by lingual-gastric and pancreatic lipases to form sn-2 monoacylglycerols and unesterified fatty acids. The sn-2 monoacylglycerols and fatty acids are absorbed into the intestinal cells, reassembled into triacylglycerols via the $s n-2$ monoacylglycerol or sn-3 glycerophosphate pathways to reform triacylglycerols and phospholipids, respectively, assembled into chylomicrons and secreted into the lymph (Small, 1991). The sn-2 monoacylglycerol pathway, in which fatty acids are reesterified with little or no specificity to the glycerol sn-1 and sn-3 position predominates in the fed state (Thompson et al., 1989). Consequently, the distribution of fatty acids in the dietary triacylglycerols determines not only whether fatty acids are absorbed as sn-2 monoacylglycerols or fatty acids but also, in part, the subsequent position of the fatty acids in the chylomicron triacylglycerols. The fatty acids hydrolyzed from the sn-1 and sn-3 position of chylomicron triacylglycerol by epithelial lipoprotein lipase are taken up by adipose, muscle, and other tissues to be beta-oxidized or accumulated as triacylglycerides for subsequent energy production. After lipoprotein lipase hydrolysis chylomicrons are transformed into remnant chylomicrons returning to the liver, where specific remnant chylomicron receptors allow their entrance into the hepatic cells. Therefore the remaining sn-2 monoacylglycerides in chylomicrons after peripheral lipoprotein lipase hydrolysis are directed to the liver. It has been proposed that the most "biologically important" fatty acids in terms of their biochemical and metabolic requirements (i.e., the essential fatty acids) must be esterified at the sn-2 position in triacylglycerols and also in phospholipids to be metabolically useful (Mortimer et al., 1998). LNA and LA in vegetable oils are most frequently esterified at the sn-2 position of triacylglycerols. The most important sources of DHA are marine oils, and over $80 \%$ of DHA in these oils is substituted at the sn-2 position of triacylglycerols and phospholipids (Sawada et al., 1993). This means that when DHA is provided from marine oils an important fraction of the LCPUFA will be transported directly to the liver to meet its metabolic requirements. Eicosapentaenoic acid (C20:5, EPA) which is another omega-3 LC-PUFA involved in many important metabolic processes, and which is an intermediary in the synthesis of DHA (Benatti et al., 2004), is also esterified in a high proportion at the sn-2 position of marine triacylglycerols and phospholipids. According to this, to obtain a good bioavailability for LC-PUFAs, the fatty acid must be preferentially esterified at the sn-2 position of triacylglycerols, phospholipids or other lipids derived from these sources, as will be further discussed.

\section{HOW TO PROVIDE DHA SUPPLEMENTATION}

After the suggestion of Expert Committees to include omega-3 LC-PUFA in infant formulas, efforts were made to identify suitable sources of DHA supplementation. Refined and deodorized fish oil was initially used because of its availability, relatively high content of DHA, and the almost absence of LA and AA. However, fish oil contains EPA which has been implicated into adverse effect in the growth of premature infants (Carlson et al., 1996). Also, a concern is that all fish oils are subjected to different levels of contamination with heavy metals and organic components. Therefore, other sources were developed. At present DHA supplementation can be provided in variable amounts and degrees of purity from different sources, such as purified free DHA or as ethyl ester derivative, extracted from single-cell algae oils, from egg yolk phospholipids, or as has been recently communicated in the form of sn-2 DHA monoacylglycerol. We discuss the advantages and disadvantages of these DHA sources to provide supplementation.

\section{Free DHA and DHA-ethyl ester}

Since fish oil contains a mixture of triacylglycerols with various fatty acids, the concentration of $\mathrm{DHA}$ may be relatively low (not higher than 18\%). However, higher concentrations of DHA can be achieved from the hydrolysis of fish oil and further separation of selected fatty acids, such as DHA or EPA by column chromatography. Pure preparations of DHA as free fatty acid or as DHA-ethyl ester have been used for supplementation. Pure DHA as free fatty acid, however, causes gastrointestinal complaints (Beckermann et al., 1990) and is very unstable to oxidation and difficult to incorporate into supplementation vehicles such as milk or formulas. In contrast to the free fatty acid, no side-effect is induced by the ethyl ester derivative. DHA-ethyl ester is less unstable than the free fatty acid, and can be incorporated into a supplementation vehicle mixed with other lipid components. DHA-ethyl ester supplementation has been used in several experimental protocols, both in humans and animals (Zuijdgeest-van Leeuwen et a., 1999). However, the absorption efficiency in the intestinal tract of the ethyl ester-derivative is controversial. Lawson and Hughes (1988) demonstrated that DHA-ethyl ester is poorly absorbed (less than $20 \%$ ) in humans when 
compared to the free fatty acid because ethyl esters are poor substrates for pancreatic lipase. However, more recently Zuijdgeest-van Leeuwen et al.,(1999), demonstrated that orally administered omega-3 fatty acid ethyl esters are efficiently hydrolyzed by rat lipase and absorbed. Moreover, our group recently demonstrated that DHA as ethyl ester may increase plasma and erythrocyte DHA content, which is a criterion for evaluating the LC.PUFA bioavailability (Valenzuela et al., 2005). Also, the DHA-ester increases the accretion of the fatty acid into the brain of rat pups when the lipid is orally administered to the dams (Valenzuela et al., 2005a). Plasma and erythrocyte fatty acid content have been considered by several authors as valid criteria to evaluate fatty acid absorption. Clinically, DHA-ethyl ester supplementation was successfully used by Martínez et al., (2000), to alleviate the symptoms of some paroxysmal child diseases that produce profound brain deficiency of DHA, such as Zellweger syndrome and its variants, neonatal adrenoleukodistrophy and infantile Refsum disease, which are characterized by metal retardation and progressive neurosensorial deterioration (Martínez, 2001).

\section{Single cell algae DHA-rich oil}

Some marine algae produce large amounts of DHA. The algae used in the commercial production of DHA-rich oil are of the Crypthecodinium cohnii strain. The manufacturing process has been described by Becker \& Kyle (1998). Briefly, the fermentation process starts with the inoculation and the transferring of the primary culture to progressively larger vessels while maintaining optimal temperature, $\mathrm{pH}$, dissolved oxygen level, and agitation. When the culture reaches the desired cell density and fatty acid content, it is harvested by centrifugation and spray-dried. Following this, the DHA-rich oil is produced in the same way that most vegetable oils are made today. The first step is extraction of the biomass with hexane in a continuous process, then the oil is desolventized under vacuum, and winterized to remove the highly saturated triacylglyceride fractions. The winterized oil is then refined, bleached and deodorized. The resulting clear, odourless algae oil is finally diluted with high-oleic sunflower oil to bring the DHA level to $40 \%$. The LC-PUFA is mainly occupying the sn-2 position of oil-triacylglycerols, which is similar to the most frequent position of DHA in human milk. Algae oil also contains AA which is at the sn-2 and the sn1 position of triacylglycerols. Antioxidants (mainly tocopherols) are added to the oil to prevent oxidation. Algae oil rich in DHA has been considered as a substance "Generally Recognized as Safe (GRAS)" with good stability and bioavailability.

\section{Egg yolk DHA phospholipids}

Egg yolk is a complex oil/water emulsion comprising of approximately $50 \%$ water, $32 \%$ lipids, $16 \%$ protein, besides carbohydrates and minerals.
A substantial part of the egg yolk lipid fraction (approx. 28\%) is formed by phospholipids. Their main components are PC (73\%), and PE (15\%). As an ingredient egg yolk phospholipids are applied in food systems to optimize micronutrients like emulsions for enhanced appearance and taste of food products. Egg yolk contains on average 0.4$0.6 \% \mathrm{DHA}$, which is mainly at the sn-2 position of PC. DHA concentration can be increased by feeding laying hens with linseed oil, canola oil, or directly with fish oil. Under these conditions DHA can be increased up to $1.2-1.5 \%$ (120-150 mg DHA/yolk). Industrially, egg yolk powder is treated with solvents to isolate lipids and phospholipids and thereafter the phospholipids are extracted by emulsifying with water followed by spray-drying. A white-yellow powder is obtained which can be easily dissolved or emulsified in water-containing mixtures (such as milk, yogurt, juices, etc). DHA in phospholipids is more resistant to oxidation than in triacylglycerols or ethyl ester (Song et al., 1997). However, natural antioxidants (such as tocopherols) are frequently added to preserve phospholipids from oxidation. Interestingly, in human subjects it has been shown that the intestinal absorption of DHA provided in the form of egg phospholipids is greater than in the form of triacylglycerols (Carnielli et al., 1998). Egg yolk phospholipids can be safely included into the mother's diet of healthy breast-fed infants and into infant formulas. As egg yolk contains a range of vitamins, minerals, protein and fats, it can be included as part of a well-balanced diet for infants and toddlers. Egg yolk phospholipids are now an important DHA source used in some infant formulas in Europe and Asia. Bondía-Martínez et al. (1998) demonstrated that infants fed formula supplemented with $0.15 \%$ DHA and $0.30 \%$ AA from egg yolk phospholipids provides a plasma and erythrocyte lipid profile similar to that found in breastfed infants during the first months of life.

\section{sn-2 DHA monoacylglycerol}

This is a new experimental source for providing $\mathrm{DHA}$ supplementation. It is a monoacylglyceride containing DHA at the sn-2 position of glycerol. The monoacylglyceride is obtained from the controlled enzymatic hydrolysis of highly refined salmon oil with an immobilized fungal stereoespecific lipase obtained from Mucor Miehei (Nieto et al., 1999). This oil, which is obtained from the processing of salmon-farming by-products, contains a high proportion of DHA (22\%-24\%) which is almost exclusively at the sn-2 position (85\%). The monoacylglyceride is separated from the other products of the enzymatic hydrolysis by silver-resin column chromatography. The monoacylglyceride has been assayed for its absence of contaminants. The bioavailability of the product was assayed in rats, showing a high intestinal absorption and producing a high DHA accretion into the brain of pups from mothers that received DHA supplementation with the monoacylglyceride before and during the gestation 
period (Valenzuela et al, 2005b). The product, which contains added $\mathrm{dl}-\alpha$ tocopherol as antioxidant, can be easily incorporated into water due its emulsifying properties that allow its incorporation into watercontaining beverages, milk, yoghurt, and also to baked products and sausages.

\section{CONCLUSIONS}

Breast-feeding is the first choice in infant nutrition. If exclusive breast-feeding is not possible or only partially possible, infant formulas must be the choice. Professionals who supervise newborn nutrition are encouraged to recommend or prescribe a number of different formulas that are available in the market. Some of these formulas contain LNA and LA from vegetable oils, others contain DHA and AA which can be obtained from the pure LC-PUFAs as ethyl esters, from single-cell algae oils, or from egg yolk phospholipids. In the near future some other preparations of omega-3 and omega-6 LC-PUFA will be available, such as monoacylglycerides or modified phospholipids. Which product is the best choice? In our opinion more basic and clinical investigation is still necessary to allow decisions based on scientific evidence and supported on physiological, biochemical, and nutritionally favourable effects. In addition, rigorous purity and toxicological testing should be conducted for fatty acid sources intended for use in commercial infant formulas.

\section{ACKNOWLEDGMENTS}

The works of the authors has been supported by FONDECYT (project 1050515), by University of los Andes (project MED 01-001), and by Ordesa SA (Spain).

\section{REFERENCES}

Agostoni, C., Trojan, S., Bellú, R., Riva, E., Bruzzese, MG., Giovannini, M. (1997).-"Developmental quotient at 24 months and fatty acid composition of diet in early infancy: a follow up study".-Arch. Dis. Child. 76, 421-424.

AI, MD., Houwelingen, AC., van Kester, AD., Hasaart, TH., Jong, AE., Hornstra, G. (1995).-"Maternal essential fatty acid pattern during normal pregnancy and their relationship to neonatal essential fatty acid status".- Br. J. Nutr. 74, 55-68.

Anderson, RE. (1970).-"Lipids of the ocular tissues. IV. A comparison of the phospholipids from the retina of six mammalian species".- Exp. Eye Res. 10, 339-344.

Anderson, JW., Johnstone, BM., Remley, DT. (1999)."Breast-feeding and cognitive development: a meta-analysis".- Am. J. Clin. Nutr. 70, 525-535.

Auestad, N., Halter, R., Hall, R., Blatter, M., Bogle, M., Burks, W., Ericson, J., Fitzgerald, K., Dobson, V., Innis, S., Singer, L., Montalto, M., Jacobs, J., Qiu, W. Bornstein, M. (2001).-"Growth and development in term infants fed long-chain polyunsaturated fatty acids: a double-masked, randomized, parallel, prospective, multivariate study".- Pediatrics 108, 372-381.

Bakker, EC., Ghys, AJ., Kester, AD., Vles, JS., Dubas, JS., Blanco, CE., Hornstra, G. (2003).-“ Long-chain polyunsaturated fatty acid at birth and cognitive function at 7 y of age".- Eur. J. Clin. Nutr. 57, 89-95.

Becker, C., Kyle, D. (1998).-"Developing functional foods containing algal docosahexaenoic acid".- Food Technol. 52, 68-71.

Beckermann, B., Beneke, M., Seitz, I. (1990)."Comparative bioavailability of eicosapentaenoic acid and docosahexaenoic acid from triacylglycerols, free fatty acids and ethyl esters in volunteers".Arzneimittelforschung 40, 700-704.

Benatti, P., Peluso, G., Nocolai, R., Calvani, M. (2004)."Polyunsaturated fatty acids: biochemical, nutritional and epigenetic properties".- J. Am. Col. Nutr. 23, 281302.

Birch, EE., Garfield, S., Hoffamn, DR., Uauy, R., Birch, DG. (2000).-"A randomized controlled trial of early dietary supply of long-chain polyunsaturated fatty acids and mental development in term infants".- Devl. Med. Child. Neurol. 42, 174-181.

Bondía-Martínez, E., López-Sabater, MC., CastelliteBargalló, Al., Rodríguez-Palmero, M., GonzálezCorbella, MJ., Rivero-Urgell, M., Campoy-Folgoso, C., Bayés-García, R. (1998).-"Fatty acid composition of plasma and erythrocytes in term infants fed human milk and formulae with and without docosahexaenoic and arachidonic acids from egg yolk lecithin".- Early Human Develop. 53, S109-S119.

Carlson, SE., Cooke, RS., Rhodes, PG. (1991).-"Effect of vegetable and marine oils in preterm infant formulas on blood arachidonic and docosahexaenoic acids".- J. Pediatr. 20, S159-S167.

Carlson, SE., Werkman, SH, Tolley, EA. (1996).-"Effect of long-chain n-3 fatty acid supplementation on visual acuity and growth of preterm infants with and without bronchopulmonary dysplasia".- Am. J. Clin. Nutr. 63, 687-697.

Clandinin, M. T., Chappell, J. E., Heim, T., Swyer, P. R., Chance, G. W. (1981).-"Fatty acid utilization in perinatal de novo synthesis of tissues".- Early Hum. Dev. 5, 355-366.

Clandinin, M. T. (1999).-"Brain development and assessing the supply of polyunsaturated fatty acids".Lipids 34, 131-137.

Cockburn, F. (1999).-"Nutrition and the brain".- In: Hansen TN. Mclntosh N, editors. Current Topics in Neonatology. 3, 93-109.

Cockburn, F. (2003).-"Role of infant dietary long-chain polyunsaturated fatty acids, liposoluble vitamins, cholesterol and lecithin on psychomotor development".- Acta Paediatr. Suppl. 442, 19-33.

Colombo, J. (2001).-"Recent advances in infant cognition: implications for long-chain polyunsaturated fatty acid supplementation studies".- Lipids 36, 919-926.

Contreras, MA., Chang, MC., Rosenberger, TA., Greiner, RS., Myers, CS., Salem, N., Rapoport, SI. (2001)."Chronic nutritional deprivation of n-3 alpha-linolenic acid does not affect n-6 arachidonic acid recycling within brain phospholipids of awake rats".- J. Neurochem. 79, 1090-1099.

Cook, AM., Low, E., Ishijimi, M. (1972).-"Effect of phosphatidylserine decarboxylase on neuronal excitation".- Nat. New Biol. 239, 150-151.

Crawford, M., Hall, B., Laurance, B., Munhambo, A. (1976).-"Milk lipid and their variability".- Curr. Med. Res. Opinion 4, 33-43. 
Crawford, M. (2000).-“Placental delivery of arachidonic and docosahexaenoic acids: implications for the lipid nutrition of preterm infants".- Am. J. Clin. Nutr. 71, 275S-284S.

Culliss, PR., DeKrui, JF. (1979).-"Lipid polymorphism and the functional roles of lipids in biological membranes".- Biochim. Biophys. Acta 559, 399-420.

Cunnane, S. (2001).-"Application of new methods and analytical approaches to research on polyunsaturated fatty acid homeostasis".- Lipids 36, 975-979.

Das, UN. (2003).-"Long-chain polyunsaturated fatty acids in growth and development of brain and memory".Nutrition 19, 62-65.

Dutta-Roy, AK. (2002).-“Transport mechanism for longchain polyunsaturated fatty acids in the human placenta".- Am. J. Clin. Nutr. 71, 315S-322S..

Ferstrom, JD. (2000).-"Can nutrient supplements modify brain function?".- Am. J. Clin. Nutr.71, 1669S-1673S.

Gale, CR., Martyn, CN. (1996).-"Breastfeeding, dummy use, and adult intelligence".- Lancet 347, 1072-1075.

Gibson, RA., Makrides, M. (2001).-"Long-chain polyunsaturated fatty acids in breast milk: are they essential?" Adv. Exp. Med. Biol. 501, 373-383.

Hansen, J., Schade, D., Harris, C., Merkel, K., Adamkin, D., Lim, M., Moya, F., Stevens, D., Twist,P. (1997)."Docosahexaenoic acid plus arachidonic acid enhance preterm infant growth. Prost. Leukotr. Essen. Fatty Acids 57, 196-199.

Hoefer, C., Hardy, MC. (1929).-“'Later development of breast fed and artificially fed infants. Comparison of physical and mental growth".- JAMA 92, 615-619.

Jeffrey, B., Weisinger, H., Neuringer, M., Mitchell, D. (2001).-"The role of docosahexaenoic acid in retinal function".-Lipids 36, 859-871.

Jensen, RG. (1999).-“Lipids in human milk”.-Lipids, 34, 1243-1271.

Jumpsen, J., Lien, E., Goh, YK., Clandinin, T. (1997)."Small changes of dietary ( $n-6)$ and (n-3)/fatty acid content ratio alter phosphatidylethanolamine and phosphatidylcholine fatty acid composition during development of neuronal glial cells in rats".- J. Nutr. 127, 724-731.

Koletzko, B., Thiel, I., Abiodun, PO. (1992).-"Fatty acid composition of human milk in Europe and Africa".- J. Pediatr. 120, S62-S70.

Koletzko, B., Sinclair, A. (1999).-"Long-chain polyunsaturated fatty acids in diets for infants: choices for recommending and regulating bodies and for manufacturers of dietary products".- Lipids 34, 215220.

Koo, WW. (2003).-“Efficacy and safety of docosahexaenoic acid and arachidonic acid addition to infant formulas: can one buy better vision and intelligence?".- J, Am. Col. Nutr. 22, 101-107.

Kurlak, LO., Stephenson, T. (1999).-"Plausible explanations for effects of long chain polyunsaturated fatty acids (LCPUFA) on neonates".- Arch. Dis. Child Fetal Neonatal Ed. 80, F148-F154.

Lagarde, M., Bernoud, N., Brossard, N., LemaitreDelaunay, D., Thies, F., Croset, M., Lecerf, J. (2001)."Lysophosphatidylcholine as a preferred carrier form of docosahexaenoic acid to the brain".- J. Mol. Neurosci. 16, 201-205.

Lawson, L., Hughes, B. (1988).-"Human absorption of fish oil fatty acids as triacylglycerols, free fatty acids, or ethyl esters".- Biochim. Biophys. Acta 152, 328-335.

Lemaitre-Delaunay, D., Pachiaudi, C., Laville, M., Pousin, J., Armstrong, M., Lagarde, M. (1999).-"Blood compartmental metabolism of docosahexaenoic acid
(DHA) in humans after ingestion of a single dose of $\left({ }^{13} \mathrm{C}\right)$-phosphatidylcholine containing DHA".- J. Lipid Res. 40, 1867-1874.

Leyton, J., Drury, PJ., Crawford, M. (1987).-“Differential oxidation of saturated and unsaturated fatty acids in vivo in the rat".- Brit. J Nutr. 57, 383-393.

Lucas, A., Stafford, M., Morley, R., Abbott, R., Stephenson, T., MacFadyen, U., Elias-Jones, A., Clements, H. (1999).-"Efficacy and safety of longchain polyunsaturated fatty acid supplementation of infant-formula milk: a randomized trial".- Lancet 354, 1948-1954.

Malcolm, CA., McCulloch, DL, Montgomery, C., Shepherd, A., Weaver, LT. (2003).-"Maternal docosahexaenoic acid supplementation during pregnancy and visual evoked potential development in term infants: a double blind, prospective, randomized trial".- Arch. Dis. Child Fetal Neonatal Ed. 88, F383-F390.

Martínez, M., Vázquez, E., García-Silva, T., Manzanares, J., Bertran, JM., Castelló, F., Mougan, I. (2000)."Therapeutic effects of docosahexaenoic acid ethyl ester in patients with generalized peroxisomal disorders".- Am. J. Clin. Nutr. 7, 376S-385S.

Martínez, M. (2001).-"Restoring the DHA levels in the brains of Zellweger patients",. J. Mol. Neorosci. 16, 309-316.

Moore, SA., Yoder, E., Murphy, S., Dutton, GR., Spector, A.-"Astrocytes non neurons produce docosahexaenoic acid and arachidonic acid".- J. Neurochem. 56, 518524.

Morgane, PJ., Austin-LaFrance, R., Bronzino, J., Tonkiss, J., Diaz-Cintra, S., Kemper, T., Galler, J. R. (1993)."Prenatal malnutrition and development of the brain".- Neurosci. Biobehav. Rev. 17, 91-128.

Mortensen, EL., Michaelsen, KF., Sanders, S., Reinisch, JM. (2002).-"The association between duration of breastfeeding and adult intelligence".- JAMA 287, 2365-2371.

Mortimer, BC., Simmonds, WJ., Joll, CA., Stick, RV., Redgrave, TG. (1998).-"Regulation of the metabolism of lipid emulsion model lipoproteins by a saturated acyl chain at the 2-position of triacylglycerol".- J. Lipid Res. 29, 713-720.

Mostofsky, D. (2001).-"Models and methods for studying behaviour in polyunsaturated fatty acid research".Lipids 36, 913-917.

Nieto, S., Gutierrez, J., Sanhueza, J., Valenzuela, A. (1999)."Preparation of sn-2 long-chain polyunsaturated monoacylglycerols from fish oil by hydrolysis with a stereo-specific lipase from Mucor Miehel'.- Grasas \& Aceites 50, 111-113.

Salem, N., Litman, B., Kim, HY., Gawrish, K. (2001)."Mechanism of action of docosahexaenoic acid in the nervous system".- Lipids 36, 945-959.

Sastry, PS. (1985).-"Lipids of the nervous tissue: Composition and metabolism".-Prog. Lipid Res. 24, 69-176.

Sawada, T., Takahashi, K., Hatano, M. (1993)."Triglyceride composition of tuna and bonito orbital fats".- Nippon Suisan Gakkaishi 59, 285-290.

Sheaff-Greiner, RC., Winter, J., Nathanielz, P., Brenna, T. (1997).-"Brain docosahexaenoic acid accretion in fetal baboon: bioequivalence of dietary $\alpha$-linolenic and docosahexaenoic acids".- Pediatr. Res. 42, 826-834.

Simopoulos, A., Leaf, A., Salem, N. (1999).-"Essentiality and recommended dietary intakes for omega- 6 and omega-3 fatty acids".- Ann. Nutr. Metab. 43, 127-130. 
Sinclair, AJ. (1975).-“Long chain polyunsaturated fatty acids in the mammalian brain".- Proc. Nutr. Soc. 34, 287-291.

Small, DM. (1991).-"The effects of glyceride structure on absorption and metabolism".-Annu. Rev. Nutr. 11, 413-434.

Song, JH., Inoue, Y., Miyasawa, T. (1997).- "Oxidative stability of docosahexaenoic acid-containing oils in the form of phospholipids, triacylglycerols, and ethyl esters".- Biosci. Biotechnol. Biochem. 61, 2085-2088.

Suzuki, H., Manabe, S., Wada, O., Crawford, M. (1997). "Rapid incorporation of docosahexaenoic acid from dietary sources into brain microsomal, synaptosomal and mitochondrial membranes in adult mice".-Int. J. Vitamin. Nutr. Res. 67; 272-278.

Thiés, F., Delachambre, MC., Bentejac, M., Lagarde, M., Lecerf, J. (1992).-“Unsaturated fatty acids esterified in 2-acyl-1-lysophosphatidylcholine bound to albumin are more efficiently taken up by the young rat brain than the unesterified form".- J. Neurochem. 59, 11101116.

Thompson, AB., Keelan, M., Garg, ML., Clandinin, T. (1989).-"Intestinal aspects of lipid absorption: in review".- Can. J. Physiol. Pharmacol. 67, 179-191.

Uauy, R., Mena, P., Rojas, C. (2000).-"Essential fatty acids in early life: structural and functional role".Proc. Nutr. Soc. 59, 3-15.

Valenzuela, A., von Bernhardi, R., Valenzuela, V., Ramírez, G., Alarcón, R., Sanhueza, J., Nieto, S. (2004).-"Supplementation of female rats with $\alpha$-linolenic acid or docosahexaenoic acid leads to the same omega-6/omega-3 LC-PUFA accretion in mother tissues and in fetal newborn brains".- Ann. Nutr. Metab. 48, 28-35.

Valenzuela, A., Valenzuela, V., Sanhueza, J., Nieto, S. (2005).-"Effect of supplementation with docosahexaenoic acid ethyl ester and sn-2 docosahexaenyl monoacylglyceride on plasma and erythrocyte fatty acids in rats".- Ann. Nutr. Metab. 49, 49-53.

Valenzuela, A., Nieto, S., Sanhueza, J., Núñez, MJ., Ferrer, C. (2005a).-"Tissue accretion and milk content of docosahexaenoic acid (DHA) in female rats alter supplementation with different DHA sources".- Ann. Nutr. Metab. 49, 325-332.

Van Houwelingen, AC., Puls, J., Hornstra, G. (1992)."Essential fatty acid status during early human development".- Early Human Dev. 31, 97-111.

Willats, P., Forsyth, JS, DiModugno, MK, Varma, S., Colvin, M. (1998).-"Effect of long-chain polyunsaturated fatty acids in infant formula on problem solving at 10 months of age".- Lancet 352, 688-691.

Zuijdgeest-van Leeuwen, S., Dagniele, P., Rietveld, T., van den Berg, JW., Wilson, P. (1999).-“Incorporation and washout of orally administered n-3 fatty acid ethyl esters in different plasma lipid fractions".- Brit. J. Nutr. $82,481-488$

Recibido: Mayo 2005 Aceptado: Noviembre 2005 